\title{
Structures of Two Water Soluble Hemolysins Isolated from the Green Alga Ulva pertusa ${ }^{\dagger}$
}

\author{
Nobuhiro FUSETANI and Yoshiro Hashimoto \\ Laboratory of Marine Biochemistry, Faculty of Agriculture, \\ The University of Tokyo, Bunkyo-ku, Tokyo
}

Received May 29, 1975

\begin{abstract}
Two water soluble hemolysins isolated from the green alga Ulva pertusa have been identified as $1^{\prime}-O$-palmitoyl-3'-O-(6-O- $\alpha$-D-galactopyranosyl- $\beta$-D-galactopyranosyl)-glycerol (1) and $1^{\prime}$ - $O$-palmitoyl-3'-O-(6-sulfo- $O$ - $\alpha$-D-quinovopyranosyl)-glycerol (2).
\end{abstract}

In our previous paper, ${ }^{1)}$ we reported that two water soluble hemolysins, substances I and II, were isolated from the green alga Ulva pertusa. The two compounds were similar to each other in biological, chemical and physical properties, and were supposed to be glycolipids.

Substance I, $\mathrm{C}_{31} \mathrm{H}_{58} \mathrm{O}_{14}$, showed IR absorption at $3400,1730,1150,1070$, and $1030 \mathrm{~cm}^{-1}$, indicative of galactosyl glycerides. ${ }^{2,3)}$ On hydrolysis with $1 \mathrm{~N}$ hydrochloric acid it yielded glycerol, galactose and palmitic acid in the molar ratio $1: 2: 1$. Deacylation of $I$ with $0.1 \mathrm{~N}$ potassium hydroxide at $37^{\circ} \mathrm{C}$ afforded an equimolar mixture of palmitic acid and 6$O-\alpha$-D - galactopyranosyl- $\beta$-D-galactopyranosyl glycerol. The latter compound had mobilities identical with those of known 6- $\alpha$-D-galactopyranosyl- $\beta$-D-galactopyranosyl-sn-glycerol in paper chromatography. ${ }^{4 \sim 6)}$ These results indicated that substance $I$ is monopalmitoyl 6-O- $\alpha$-D-galactopyranosyl- $\beta$-D-galactopyranosyl glycerol.

The position of attachment of palmitic acid was confirmed by the mass and NMR spectra of the trimethylsilyl (TMS) derivative. The mass spectrum with prominent ion peaks at $m / e$ 401, 385, 371, 269, and 239 indicated that the 2-position of glycerol is not substituted. These ions may be interpreted by fragmentation scheme 3. ${ }^{7)}$ The mass spectrum of the acetate also supported this struc-

$\uparrow \quad$ Studies on Marine Toxins. Part XLVIII.
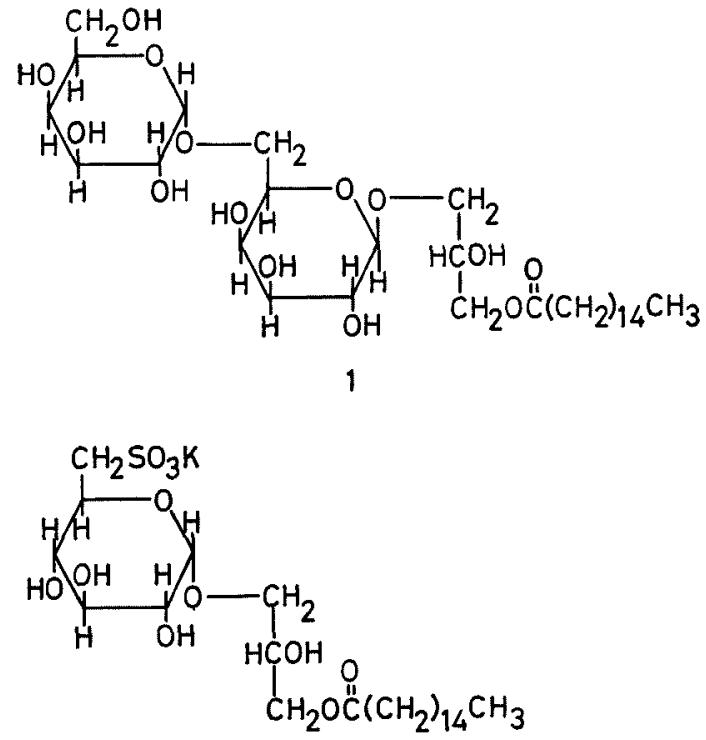

2

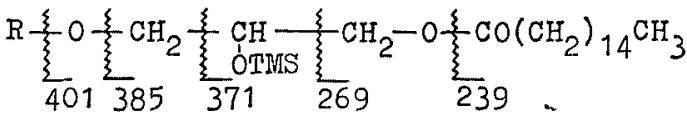

$$
\begin{aligned}
& 3 \mathrm{R}=\text { sugar moiety }
\end{aligned}
$$

ture. Since the TMS derivative gave no ions beyond $m / e 700$ by the direct inlet method, GC-MS analysis using a short glass column was attempted. A single peak with a small shoulder was obtained in gas chromatography, and ion peaks as high as $m / e 991$ were observed. Beside the peaks mentioned above, prominent ion peaks at $m / e 204$ (base), 217, $241,271,281,309,319,341,361$, and 475 

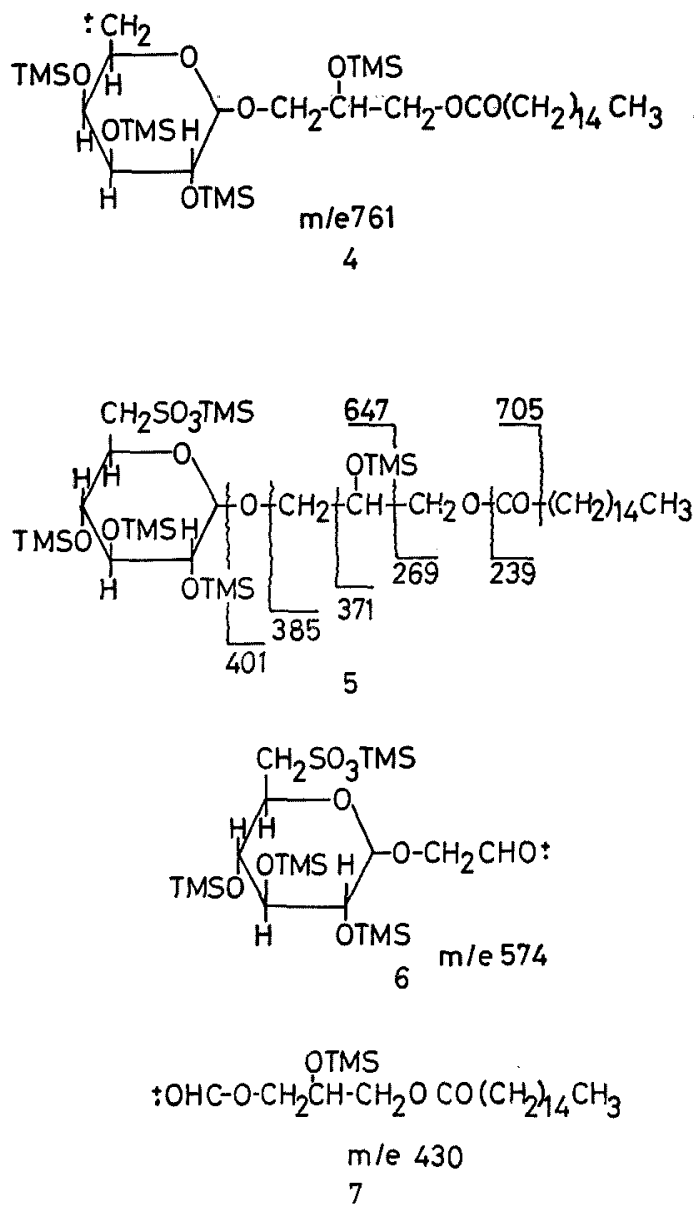

were observed. These peaks were supposed to be fragment ions derived from the sugar moiety ${ }^{8,9)}$ An intense peak at $m / e 761$ may be attributable to fragment ion (4). Peaks at $m / e 991\left(\mathrm{M}^{+}-239\right)$ and $829\left(\mathrm{M}^{+}-401\right)$ were also recognized, though no parent ion was obtained.

The NMR spectrum of the TMS derivative in deuterochloroform gave further information on the unsubstituted 2-position of glycerol moiety. One terminal methyl of the palmitoyl group appeared as a triplet at $\delta 0.79$, methylene protons at $\delta 1.14$ (singlet) and $\alpha$ methylene protons at $\delta 2.25$ (triplet). Complex signals from $\delta 3.2$ to $\delta 4.3$ and an $\alpha$ anomer proton $^{10)}$ of the galactosyl group at $\delta$ 4.66 (doublet, $J \simeq 3 \mathrm{~Hz}$ ) were observed. $\mathrm{Ab}$ sence of low field signals strongly indicated that the 2-position of glycerol is not conju- gated. ${ }^{11}$ These values also coincided well with those reported for synthetic $1^{\prime}$-O-palmitoyl-3'-O-(6-O- $\alpha$-D-galactopyranosyl- $\beta$-D-galactopyranosyl)-sn-glycerol. ${ }^{12)}$ Structure (1) is therefore assigned to substance I.

Substance II, $\mathrm{C}_{25} \mathrm{H}_{47} \mathrm{O}_{11} \mathrm{SK}$, gave no sulfuric acid upon hydrolysis.' Its IR spectrum exhibited absorption bands at 3400,1730, 1170, 1150, 1060,1035 , and $771 \mathrm{~cm}^{-1}$, indicative of 6 sulfoquinovosyl glycerides. ${ }^{2,13}$ Strong bands at $1170,1060,1035$, and $771 \mathrm{~cm}^{-1}$ suggested the presence of a sulfonyl group. ${ }^{14)}$ With anthrone reagent the compound produced a blue color with $\lambda_{\max } 592 \mathrm{~nm}$, characteristic of 6-sulfoquinovose. ${ }^{15)}$

Acid hydrolysis of substance II with $1 \mathrm{~N}$ hydrochloric acid afforded glycerol, 6-sulfoquinovose and palmitic acid in the molar ratio $1: 1: 1$. Upon mild alkaline hydrolysis with $0.1 \mathrm{~N}$ potassium hydroxide it released an equimolar mixture of palmitic acid and 6sulfo- $\alpha$ - $D$-quinovopyranosyl glycerol. The latter compound showed mobilities quite similar to those of known 6-sulfo- $\alpha$-D-quinovopyranosyl-sn-glycerol. ${ }^{5,16)}$ These results led us to assume that substance II has the structure of monopalmitoyl 6-sulfo- $\alpha$-D-quinovopyranosyl glycerol.

The mass spectrum of the TMS derivative indicated that the 2-position of glycerol is not involved in ester linkage, as in the case of substance I. In GC-MS analysis, the TMS derivative exhibited a single peak and prominent ion peaks at $m / e$ 204 (base), 371, 385, 430, 485,574 , and 705 , though no parent ion peak was observed. These fragment ions may be assigned as shown in (5). Intense ion peaks at $m / e 574$ and 430 may be attributable to (6) and (7), respectively.

The NMR spectrum of the TMS derivative in deuterochloroform gave further confirmation for the 2-position of the glycerol moiety. One terminal methyl of the palmitoyl moiety was observed at $\delta 0.78$ (triplet), a large methylene signal at $\delta 1.17$ (singlet), and an $\alpha$-methylene signal at $\delta 2.20$ (triplet). An $\alpha$-anomer proton ${ }^{10\}}$ of the sugar moiety appeared as a doublet at $\delta 4.74(J \simeq 3 \mathrm{~Hz})$. Lack of low field signals 
indicated the absence of substitution at the 2-position of glycerol. ${ }^{11}$ These data allow us to conclude that substance II has structure (2).

To our knowledge, this is the first time that a lysogalactolipid and lysosulfolipid were isolated pure, while their presence had been postulated for many years. ${ }^{4,17,18)}$ It is very interesting that only palmitic acid was obtained on hydrolysis, since every glycolipid isolated so far released a mixture of fatty acids. ${ }^{19)}$ We previously isolated palmitic acid as the fat soluble hemolysin, which is the predominant fatty acid in the alga. ${ }^{1)}$ It is most likely that palmitic acid plays a unique role in the physiology of the green alga $U$. pertusa.

\section{EXPERIMENTAL}

IR spectra were measured with a JASCO IR-S spectrometer. NMR spectra were recorded on a JEOLJNM-4H spectrometer and mass spectra on a Hitachi RMU-6L mass spectrometer. GC-MS analyses were carried out with an LKB 9000 GC-MS system. Gas liquid chromatography (GLC) was performed on a Shimadzu GC-5A instrument equipped with hydrogen flame ionization detector.

Fatty acids were derivatized to their methyl esters by the method of Horning et al. ${ }^{201}$ and analyzed on glass columns $(3 \mathrm{~mm} \times 2 \mathrm{~m})$ packed with $5 \% \mathrm{SE}-30$ on Shimalite W (60/80) and with $20 \%$ DEGS on Shimalite $\mathrm{W}(60 / 80)$. The former column was operated by linear programming at $4^{\circ} \mathrm{C} / \mathrm{min}$ from 100 to $230^{\circ} \mathrm{C}$, and the latter isothermally at $190^{\circ} \mathrm{C}$.

Trimethylsilyl ethers (TMS) for GLC analyses were prepared by the method of Sweeley et al. ${ }^{211}$ using dimethylformamide (DMF), N,O-bis-(trimethylsilyl)trifluoroacetamide (BSTFA) and trimethylchlorosilane (TMCS). GLC analyses of the acid hydrolysis products were carried out on a glass column $(3 \mathrm{~mm} \times 2 \mathrm{~m})$ packed with $3 \%$ OV-1 on Shimalite W $(60 / 80)$. The column temperature was maintained at $70^{\circ} \mathrm{C}$ for $5 \mathrm{~min}$ and programmed at $10^{\circ} \mathrm{C} / \mathrm{min}$ to $180^{\circ} \mathrm{C}$ then at $4^{\circ} \mathrm{C} / \mathrm{min}$ to $250^{\circ} \mathrm{C} .{ }^{221}$ Ethylene glycol was used as the internal standard and peak areas were measured by triangulation. The TMS derivatives of intact hemolysins were analyzed on a $1 \mathrm{~m}$ column packed with $1.5 \% \mathrm{OV}-1$ on Shimalite W $(60 / 80)$. The TMS derivatives for measurement of NMR spectra were prepared according to Kamerling et al. ${ }^{10}$ ) and the spectra were taken in deuterochloroform with tetramethylsilane as theinternal standard.

Thin-layer chromatography was carried out on silica gel H (Merck) with benzene-acetone (4:1) (solvent $a$ ) and $n$-hexane-diethyl ether-acetic acid $(70: 30: 1)$ (solvent $b$ ). For detection of components plates were sprayed with $50 \%$ sulfuric acid and $10 \%$ phosphomolybdic acid. Paper chromatography was performed by the ascending technique with Toyo No. 51 paper. Solvents used were 2-propanol-pyridine-water-acetic acid $(8: 8: 4: 1)$ (solvent $c$ ), 1-butanol-pyridine-water (6:4:3) (solvent $d$ ), 1-butanol-propionic acid-water (142: $71: 100)$ (solvent $e$ ), phenol-water $(100: 40, \mathrm{v} / \mathrm{v}$ ) (solvent $f$ ), phenol-water $(100: 40, \mathrm{w} / \mathrm{w}$ ) (solvent $g$ ), and water-saturated 2,4,6-trimethylpyridine (solvent $h$ ). The components were detected by spraying with $p$ anisidine- $\mathrm{HCl}$, aniline phthalate, diphenylamine, and periodate-benzidine reagents.

\section{Isolation of substances I and II}

Isolation and some properties of the hemolysins were reported in the previous paper. ${ }^{11}$

TMS derivative of substance I, colorless gum, NMR: $\delta 0.79$ (triplet), 1.14 (singlet), 2.25 (triplet), 3.2 4.3 (complex signals), 4.66 (doublet, $J \simeq 3 \mathrm{~Hz}$ ); MS: $m / e$ $117,129,149,167,239$ (base), 257, 269, 281, 313, 341, $369,371,385,401,415,549,625$.

Acetate of substance $\mathrm{I}, \mathrm{mp} 56 \sim 57^{\circ} \mathrm{C}$, MS: $\mathrm{m} / \mathrm{e} 117$, $129,171,239$ (base), 269, 313, 331, 341, 355, 381, 523, $551,579$.

TMS derivative of substance II, colorless gum, NMR: $\delta 0.78$ (triplet), 1.17 (singlet), 2.20 (triplet), $3.0 \sim 4.2$ (complex signals), 4.74 (doublet, $J \simeq 3 \mathrm{~Hz}$ ); MS: $m / e$ 117, 171, 185, 239 (base), 257, 269, 311, 331, $341,355,371,385,401,429,465,550,625$.

\section{Acid hydrolysis of substance I}

A $2 \mathrm{mg}$ portion of substance $\mathrm{I}$ dissolved in $1 \mathrm{~N}$ hydrochloric acid $(1 \mathrm{ml})$ was heated at $100^{\circ} \mathrm{C}$ for $2 \mathrm{hr}$. The reaction mixture was extracted with diethyl ether after addition of water. The aqueous layer was freed from hydrochloric acid by repeated evaporation and examined by paper chromatography. The presence of glycerol and galactose was recognized as shown in Table I.

The ether extract gave only one spot on silica gel $\mathrm{H}$ layers, when developed with solvents $a$ and $b$. GLC analysis of the methyl ester showed the presence of palmitic acid. The residue was recrystallized from $80 \%$ ethanol and obtained as white scales with $\mathrm{mp} 63 \sim$ $63.5^{\circ} \mathrm{C}$, coinciding with an authentic sample of palmitic acid in IR and mass spectra.

Table I. $R f$ Values of the Water Soluble Products ObTaIned by Acid Hydrolysis OF SUBSTANCE I

\begin{tabular}{cccc}
\hline Solvent & Glycerol & Products & Galactose \\
\hline$c$ & 0.78 & $0.78,0.54$ & 0.54 \\
$d$ & 0.58 & $0.58,0.33$ & 0.33 \\
$e$ & 0.47 & $0.48,0.21$ & 0.21 \\
$f$ & 0.63 & $0.63,0.36$ & 0.36 \\
\hline
\end{tabular}


Table II. Determination of the Acid HydRolyzates By Gas LiQuid Chromatography

\begin{tabular}{|c|c|c|}
\hline Sample & Retention time (min) & Molar ratio \\
\hline Glycerol & 13.6 & \\
\hline Galactose & $23.0,23.6,24.5$ & \\
\hline Palmitic acid & 25.6 & \\
\hline Hydrolyzates & $22.9, \begin{array}{l}13.6 \\
23.6, \\
25.6\end{array}$ & $\begin{array}{l}1 \\
1.8 \\
0.9\end{array}$ \\
\hline
\end{tabular}

\section{Determination of the acid hydrolysis products}

One milligram of substance I was hydrolyzed and freed from hydrochloric acid. To the residue were added DMF $(100 \mu 1)$, BSTFA $(40 \mu 1)$ and TMCS $(20 \mu 1)$, and the mixture was heated at $80^{\circ} \mathrm{C}$ for $10 \mathrm{~min}$. One $\mu \mathrm{l}$ of the reaction mixture was subjected to GLC analysis (Table II).

\section{Deacylation of substance I}

To $25.8 \mathrm{mg}$ of substance I dissolved in $1 \mathrm{ml}$ of water was added $1 \mathrm{ml}$ of $0.2 \mathrm{~N}$ potassium hydroxide, and the solution was kept at $37^{\circ} \mathrm{C}$ for $24 \mathrm{hr}$. The reaction mixture was acidified with cation resin, AG 50W-X8 $\left(\mathrm{H}^{+}\right.$form) and extracted with diethyl ether. On evaporation to dryness, the aqueous layer afforded colorless solids $(14.1 \mathrm{mg})$. Paper chromatographic analysis with solvents $c(R f 0.11), d(0.12), e(0.51)$, and $h$ ( $\mathbf{R}_{\text {ga a actose }} 0.40$ ) indicated the presence of $6-\mathrm{O}-\alpha-\mathrm{D}-$ galactopyranosyl- $\beta$-D-galactopyranosyl glycerol. ${ }^{4 \sim 6 \text { । }}$

The ether extract gave colorless scales $(11.6 \mathrm{mg})$ upon evaporation. The residue was recrystallized from $80 \%$ ethanol to afford colorless scales with $\mathrm{mp} 63 \sim$ $63.5^{\circ} \mathrm{C}$ (Found: $\mathrm{C}, 75.00 ; \mathrm{H}, 12.31 . \quad \mathrm{C}_{16} \mathrm{H}_{32} \mathrm{O}_{2}$ requires $\mathrm{C}, 74.94 ; \mathrm{H}, 12.58 \%$ ). This compound was identical with palmitic acid in GLC, IR and mass spectra.

\section{GC-MS analysis of the TMS derivative of substance I}

One milligram of substance I was trimethylsilylated with BSTFA $(40 \mu \mathrm{l})$ and TMCS $(20 \mu \mathrm{l})$ in DMF $(100 \mu \mathrm{l})$ and analyzed by GLC. The column temperature was maintained at $270^{\circ} \mathrm{C}$ for $1 \mathrm{~min}$ and then programmed at $4^{\circ} \mathrm{C} / \mathrm{min}$ to $330^{\circ} \mathrm{C}$. A single peak with a small shoulder was obtained. For GC-MS analysis, the temperature programming was set at $2^{\circ} \mathrm{C} / \mathrm{min}$ from 290 to $300^{\circ} \mathrm{C}$. MS: $\mathrm{m} / \mathrm{e} 204$ (base), 217, 231, 243, 271, 281, 305, 341, 361, 385, 401, 451, 731, 761, 829, 991.

\section{Acid hydrolysis of substance II}

Two milligrams was hydrolyzed in $1 \mathrm{ml}$ of $1 \mathrm{~N}$ hydrochloric acid in the same manner as described for substance I. The aqueous layer was freed from the acid and analyzed by paper chromatography. As shown in Table III, the presence of glycerol and 6sulfoquinovose was recognized. The latter compound
TABle III. $R f$ Values of the Water Soluble Products Obtained by Acid Hydrolysis of Substance II

\begin{tabular}{lccc}
\hline Solvent & Glycerol & Products & $\begin{array}{c}\text { 6-Sulfo- } \\
\text { quinovose }\end{array}$ \\
\hline$c$ & 0.78 & $0.78,0.20$ & 0.20 \\
$d$ & 0.58 & $0.58,0.08$ & 0.08 \\
$e$ & 0.48 & $0.48,0.08$ & 0.08 \\
$g$ & 0.70 & $0.70,0.12$ & 0.12 \\
\hline
\end{tabular}

coincided well with an authentic specimen synthesized by the method of Miyano and Benson. ${ }^{23}$

The ether extract afforded white solids, identical with an authentic specimen of palmitic acid in GLC, IR and mass spectra.

\section{Determination of the acid hydrolysis products}

One milligram of the compound was hydrolyzed and the trimethylsilylated mixture was analyzed by GLC in the same manner mentioned above. It was found that glycerol, 6-sulfoquinovose and palmitic acid were present in the molar ratio $1: 1: 1$.

\section{Mild alkaline hydrolysis of substance II}

To a $51.2 \mathrm{mg}$ portion dissolved in $2.5 \mathrm{ml}$ of water was added $2.5 \mathrm{ml}$ of $0.2 \mathrm{~N}$ potassium hydroxide. The mixture was kept at $37^{\circ} \mathrm{C}$ for $24 \mathrm{hr}$ and $31.3 \mathrm{mg}$ of colorless solids was obtained as the water soluble product after usual work-up. Paper chromatography with solvents $c(R f 0.19), e(0.08)$ and $g(0.20)$ suggested the presence of 6-sulfo-O- $\alpha$-D-quinovopyranosyl glycerol..$^{5,161}$

The ether soluble fraction upon evaporation gavewhite scales $(19.1 \mathrm{mg})$ identical with palmitic acid in $\mathrm{mp}$, combustion analysis, IR and mass spectra.

GC-MS analysis of the TMS derivative of substance II

The TMS derivative of substance II was prepared by the routine method and analyzed on a $1 \mathrm{~m}$ glass column of $1.5 \% \mathrm{OV}-1$ with temperature programming. at $2^{\circ} \mathrm{C} / \mathrm{min}$ from $270^{\circ} \mathrm{C}$. Only one peak appeared and showed ion peaks at $m / e 204$ (base), 217, 271, 281, 313, $339,361,371,385,401,430,485,574,576,647$, and 705 .

Acknowledgements. This work was supported by the fund from the Ministry of Education. We are grateful to Professor Tamao Yoshida, Tokyo University of Fisheries for GC-MS analyses and to Dr. Kazuyuki Aizawa of this University for measurement of IR, NMR and mass spectra. Thanks are also due to Professor Paul J. Scheuer, Department of Chemistry, University of Hawaii at Manoa, who kindly read our manuscript. 


\section{REFERENCES}

1) N. Fusetani and Y. Hashimoto, Proc. 4th Int. Symp. Animal, Plant and Microbial Toxins, 1974 in press

2) C. F. Allen, P. Good, H. F. Davis, P. Chisum and S. W. Fowler, J. Amer. Oil Chem. Soc., 43, 223 (1966).

3) P. S. Sastry and M. Kates, Biochemistry, 3, 1271 (1964).

4) F. A. Exterkate and J. H. Veerkamp, Biochim. Biophys. Acta, 176, 65 (1969).

5) R. A. Ferrari and A. A. Benson, Arch. Biochem. Biophys., 93, 185 (1962).

6) H. E. Carter, R. H. McCluer and E. D. Slifer, $J$. Amer. Chem. Soc., 78, 3735 (1959).

7) G. Odham and E. Stenhagen, "Biochemical Applications of Mass Spectrometry," John Wiley \& Sons, Inc., 1972, p. 157.

8) D. C. DeJongh, T. Radford, J. D. Hribar, S. Hanessian, M. Bieber, G. Dawson and C. C. Sweeley, J. Amer. Chem. Soc., 91, 1728 (1969).

9) J. P. Kamerling, J. F. G. Vliegenthart, J. Vink and J. J. de Ridder, Tetrahedron, 27, 4275 (1971).

10) J. P. Kamerling, D. Rosenberg and J. F. G.
Vliegenthart, Biochem. Biophys. Res. Commun., 38, 794 (1970).

11) B. Serdarevich, I. Amer. Oil Chem. Soc., 44, 381 (1967).

12) O. M. R. A. Heisig and E. Heinz, Phytochemistry, 11, 815 (1972).

13) A. Radunz, Hoppe-Seyler's Z. Physiol. Chem., 350, 411 (1969).

14) K. Fujimori, Bull. Chem. Soc. Japan, 32, 850 (1959).

15) R. O. Weenink, Nature, 197, 62 (1963).

16) T. Yagi and A. A. Benson, Biochim. Biophys. Acta, 57, 601 (1964).

17) S. Sato, Nippon Suisan Gakkaishi, 37, 326 (1971).

18) T. A. MacMurray and W. R. Morrison, J. Sci. Food Agr., 21, 520 (1970).

19) M. Kates, Adv. Lipid Res., 8, 225 (1970).

20) J.-P. Thenot, E. C. Horning, M. Stafford and M. Horning, Anal. Lett., 5, 217 (1972).

21) R. A. Laine, W. J. Esselman and C. C. Sweeley, Methods in Enzymol., 28, 159 (1973).

22) G. G. S. Dutton, K. B. Gibney, G. D. Jensen and P. E. Reid, J. Chromatogr., 36, 152 (1968).

23) M. Miyano and A. A. Benson, J. Amer. Chem. Soc., 84, 59 (1962). 